\title{
The evolution and future of diabetic kidney disease research: a bibliometric analysis
}

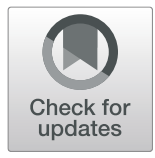

Yi Wei and Zongpei Jiang*

\begin{abstract}
Background: Diabetic kidney disease (DKD) is one of the most important complications of diabetic mellitus. It is essential for nephrologists to understand the evolution and development trends of DKD.

Methods: Based on the total cited numbers in the Web of Science Core Collection, which was searched through September 28th, 2020, we performed a bibliometric analysis of the top 100 most cited full-length original articles on the subject of DKD. The timespans, authors, contributions, subcategories, and topics of those 100 articles were analysed. In addition, the evolution of topics in DKD research was investigated.

Results: There were 23,968 items under the subject of DKD in the Web of Science Core Collection. The top 100 cited articles, published from 1999 to 2017, were cited 38,855 times in total. Researchers from the USA contributed the most publications. The number of articles included in 'Experimental studies (EG)', 'Clinical studies (CS)', 'Epidemiological studies (ES)', and 'Pathological and pathophysiological studies (PP)' were 65, 26, 7, and 2, respectively. Among the 15 topics, the most popular topic is the renin-angiotensin-aldosterone system (RAAS), occurring in 26 articles, including 6 of the top 10 most cited articles. The evolution of topics reveals that the role of RAAS inhibitor is a continuous hotspot, and sodium-glucose cotransporter 2 (SGLT-2) inhibitor and glucagon-like peptide 1 (GLP-1) agonist are two renoprotective agents which represent novel therapeutic methods in DKD. In addition, the 26 clinical studies among the top 100 most cited articles were highlighted, as they help guide clinical practice to better serve patients.
\end{abstract}

Conclusions: This bibliometric analysis of the top 100 most cited articles revealed important studies, popular topics, and trends in DKD research to assist researchers in further understanding the subject.

Keywords: DKD, RAAS, ACE2, SGLT-2, Bibliometric analysis

\section{Background}

Diabetes mellitus (DM) is a severe global health problem and contributes to increased health care costs. It is estimated that more than 450 million people are affected by this disease, and this number will reach 700 million people by 2045 [1]. Diabetic kidney disease (DKD) is one of the most important complications of DM, and chronic kidney disease occurs in more than $20-40 \%$ of DM patients [2]. Thus, overall comprehension of the mechanism and

\footnotetext{
* Correspondence: jiangzp@mail.sysu.edu.cn

Department of Nephrology, The Sixth Affiliated Hospital, Sun Yat-sen

University, 26 Yuancun Er Heng Road, Guangzhou 510655, China
}

treatment of DKD is essential for nephrologists, especially young researchers.

Recent reviews have helped researchers understand the mechanism, diagnosis, and treatment of DKD, as summarized in Table S1. These studies highlight the vital roles of immunity and inflammation [3-5], oxidative stress (OS) [6-8], haemodynamic and metabolic shifts [9], epigenetic factors [10] and tubule function [11] in the pathogenesis and prognosis of DKD. However, these content-based reviews have 3 limitations. First, the review contents are deep but narrow, which makes it difficult for readers to understand the overall research status of the subject. Second, the articles referenced in the reviews were manually selected. The large

(c) The Author(s). 2021 Open Access This article is licensed under a Creative Commons Attribution 4.0 International License, which permits use, sharing, adaptation, distribution and reproduction in any medium or format, as long as you give appropriate credit to the original author(s) and the source, provide a link to the Creative Commons licence, and indicate if changes were made. The images or other third party material in this article are included in the article's Creative Commons licence, unless indicated otherwise in a credit line to the material. If material is not included in the article's Creative Commons licence and your intended use is not permitted by statutory regulation or exceeds the permitted use, you will need to obtain permission directly from the copyright holder. To view a copy of this licence, visit http://creativecommons.org/licenses/by/4.0/ The Creative Commons Public Domain Dedication waiver (http://creativecommons.org/publicdomain/zero/1.0/) applies to the data made available in this article, unless otherwise stated in a credit line to the data. 
workload leads to limited numbers. However, subjective judgement may lead to the loss of information. Authors may miss important research. Even if an article is cited, its importance and influence may be neglected. Third, readers cannot learn the evolution of the subject or evolution of popular topics and thus cannot develop a deeper comprehension of the subject.

Clinical and experimental studies on DKD have developed rapidly. In total, there were 23,968 items in the Web of Science Core Collection on the subject of DKD from 1999 to September 28th, 2020. In a sense, the citation time (CT) represents the influence and significance of the article. Bibliometric analysis is a method utilized in many fields to illustrate the landscape of subjects [12, 13]. Based on CT, bibliometric analysis objectively includes articles of subject on subject in the analysis and reflects the evolution of a subject, trends of popular topics and collaborative relationships among researchers and countries [14-16]. To determine the influential research, the distribution of disparate topics and the evolution of research trends, we performed a bibliometric analysis of the top 100 most cited articles in clinical and experimental studies of DKD.

\section{Materials and methods}

\section{Data collection and filtration}

To acquire literature data representing high-quality research, we retrieved publications on the subject of DKD from the Web of Science Core Collection using the search strategy: TOPIC: (DKD OR (diabetic NEAR/0 nephropathy) OR (diabetic NEAR/0 kidney)). Research results were ranked by $\mathrm{CT}$, which was based on the absolute number of citations for each article through September 28th, 2020. Articles involving the following research objects were defined as publications on the subject of DKD and were manually selected: DKD populations; diabetes populations with proteinuria or kidney disease; tissue, blood, or urine from DKD and diabetes patients with proteinuria or kidney disease; diabetic animals with kidney injury; and renal cell models simulating diabetes injury. Only full-length original articles were included in this study while other types of articles, such as guidelines, reviews, and metaanalyses, were excluded. Finally, only the top 100 most cited full-length original articles written in English on the subject of DKD were included in this study.

\section{Data analysis and visualization}

Elements including the article title, author, address, abstract, keyword, journal, publication year and CT were included in the analysis. The article number was equal to the article rank among the 100 articles. The relevant countries were analysed according to the corresponding authors. If the corresponding authors came from the same country, the article was defined as a single-country publication; otherwise, it was defined as a multi-country publication. Subcategories and topics were manually summarized and counted. The average citation time (ACT) of each article was equal to the CT divided by the number of years the article was cited, and the number of years the article was cited was equal to 2020 plus 1 minus the number of the published year. In addition, the number of citations per article per year was equal to the sum of ACTs of all articles published in the same year divided by the number of articles. The author's influence score was represented by the sum of the ACT, and one article was scored on only the publication year.

Bibliometric analysis was performed using the Bibliometric R Package [17]. Journal analysis was performed using the module of most relevant sources. Country analysis was performed using the module of the corresponding author's country. The frequencies of key words included in the word cloud were determined using the module of most frequent words with abstract parameters.

Figures were made by Microsoft PowerPoint, ggplot2 R Package, and ggwordcloud R Package. The process of data preparation and analysis is shown in Fig. 1.

\section{Results}

Basic information of the top 100 most cited articles

As shown in Table 1, the top 100 most cited articles were published in 26 journals, and 55\% of the articles were published in the following 4 journals: Journal of the American Society of Nephrology (21\%), Diabetes (16\%), Kidney International (10\%), and The New England Journal of Medicine (8\%).

The 100 articles were published from 1999 to 2017 and were cumulatively cited 38,855 times. The publication time spans are shown in Fig. 2. There were 20 articles published from 1999 to 2002, 38 articles published from 2003 to 2007, 31 articles published from 2008 to 2012 and 11 articles published from 2013 to 2017. In 2003, 13 articles were published, which made 2013 the year with the most publications.

Finally, we analysed the authors, and their affiliations, of the top 100 most cited articles. The authors shown in Figure S1 were the top 10 most relevant authors ranked by the author's influence score. The dot size represents the score of authors, and the dot colour reflects the number of works published by the author. In Table 2, we found that scientists from the USA contributed the most publications.

\section{Identification of the subcategories of the top 100 articles} We divided the articles into 4 subcategories according to the research type and content. The most abundant article subcategory was 'Experimental studies (EG)', which explained the phenotypic changes and mechanisms in experimental DKD and comprised 65 articles $(49.62 \%$ of 

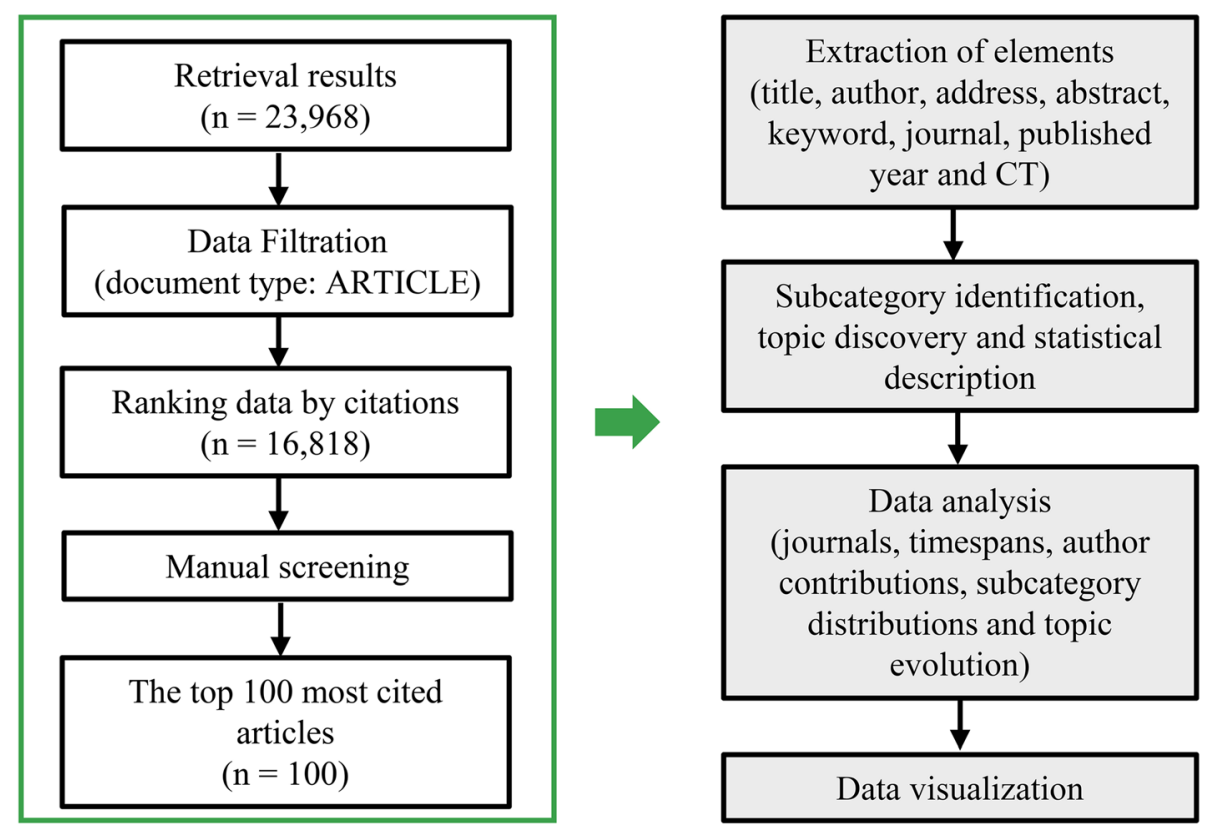

Fig. 1 Strategy for data preparation and analysis. We retrieved publications on the subject of DKD from the Web of Science Core Collection and ranked the top 100 most cited articles. After subcategory and topic identification, we performed analyses of the journals, countries, author contributions, distributions and topic evolution

all citations). The second most abundant subcategory was 'Clinical studies (CS)', which focused on the clinical biomarkers and treatment strategies for DKD, and in this subcategory, 26 articles contributed to $41.55 \%$ of the total citations. Moreover, 7 articles with 2603 total citations were determined to belong to the subcategory 'Epidemiological studies (ES)', and 2 articles specifically describing the pathological and pathophysiological characteristics of DKD belonged to the subcategory 'Pathological and pathophysiological studies (PP)'. In Table 3, we list the article number and percentage of total citations for each subcategory.

To learn more about the contents of the 100 articles, we analysed the key words. Figure 3 shows the highly frequent words related to the top 100 most cited articles on DKD. To further determine the hotspots in DKD research, we analysed articles in the subcategories 'EG' and 'CS' by their topic. In Table 4, we list the top 100 most cited articles and their topics.

\section{Distributions of the top 100 most cited articles in regard to different subcategories, topics and periods}

In Fig. 4, we show the distribution of the top 100 most cited articles. We divided the year of publication into 4 periods. The distributions of the 100 articles are shown in Fig. 4a. Most 'CS' articles were published from 2003 to 2007 (Fig. 4b), while most 'MG' articles were published from 2008 to 2012 (Fig. 4c).
Intriguingly, we revealed popular research fields via topic analysis. We found that the renin-angiotensinaldosterone system (RAAS) was the most popular topic. Clinical trials on the application of RAAS blockade in DKD (article number 1, 2, 3, 7, 9, 10, 15, 27, 41, 52, 62, 64, 75, and 86 , a total of 11,852 citations, $30.50 \%$ of the total citations) included 6 of the top 10 most cited articles, which contributed to $26.52 \%$ of the total citations. Correspondingly, 6 articles (article number 25, 39, 71, 84,92 , and 95 , a total of 1579 citations, $4.06 \%$ of the total citations) explained the mechanism of RAAS in DKD. In addition, RAAS blockade-based combination treatment was also popular among researchers, as it was associated with 6 articles that were cited 1756 times (4.52\% of the total citations). RAAS blockade combined with vitamin D analogues (article number 17, 97) and mineralocorticoid antagonism (article number 35, 80, 93) were recommended for renal function protection, but RAAS combined with the endothelin antagonist avosentan (article number 50) was considered to induce fluid overload. Taken together, these data indicated the crucial role of RAAS blockade in therapeutic strategies for DKD.

The next most important topic was how the OS participates in DKD, which was associated with 17 articles published from 2000 to 2013 (article number 5, 18, 22, $24,45,55,63,67,70,72,73,81,85,88,89,91$, and 100 , a total of 5080 citations, $13.07 \%$ of the total citations). In experimental DKD, the increase in reactive oxygen 
Table 1 List of the relevant scientific journals

\begin{tabular}{ll}
\hline Journal & Number of articles \\
\hline J Am Soc Nephrol & 21 \\
Diabetes & 16 \\
Kidney Int & 10 \\
N Engl J Med & 8 \\
J Clin Invest & 6 \\
JAMA & 4 \\
J Biol Chem & 4 \\
Am J Physiol Renal Physiol & 3 \\
Hypertension & 3 \\
Nat Med & 3 \\
Proc Natl Acad Sci U S A & 3 \\
Am J Pathol & 2 \\
Diabetes Care & 2 \\
FASEB J & 2 \\
Nephrol Dial Transplant & 2 \\
Am J Kidney Dis & 1 \\
Am J Nephrol & 1 \\
Ann Intern Med & 1 \\
Arch Intern Med & 1 \\
Biochim Biophys Acta & 1 \\
Cell Metab & 1 \\
Circulation & 1 \\
Diabetes Obes Metab & 1 \\
Diabetologia & 1 \\
Lancet & 1 \\
Nat Cell Biol & 1 \\
\hline & 1 \\
\hline
\end{tabular}

species (ROS) (article number 5) and $\mathrm{NAD}(\mathrm{P}) \mathrm{H}$ oxidase levels (article number 22, 63, 67, and 91), activation of PKC (article number 24 and 81), decrease in eNOS (article number 55, 85, and 100) and mitochondrial dysfunction (article number 70, 72, and 89) promote OS injury, while Nrf2 (article number 45, 73, and 88) protects the kidney from OS in DKD as an antioxidant factor. However, a phase 3 clinical study (article number 18) found that the Nrf2 activator bardoxolone methyl did not ameliorate the loss of renal function. Instead, bardoxolone methyl led to a higher cardiovascular risk.

The accumulation of advanced glycation end products (AGEs) is also a classic pathogenic mechanism in DKD. Among the top 100 most cited articles, 7 articles (article number $19,21,30,38,44,51$, and 60 , a total of $2322 \mathrm{ci}-$ tations) focused on AGEs and the receptor for AGEs (RAGE), which constituted $5.98 \%$ of the total citations. Although they slowed the progression of experimental DKD, agents targeting AGEs/RAGE were not easily translated into the clinic. In a randomized clinical trial, pimagedine, an inhibitor of AGE formation, did not ameliorate nephropathy in patients with type 1 diabetic mellitus (T1DM) (article number 44).

In addition to therapies developed based on classic mechanisms, researchers have highlighted new drugs developed based on new mechanisms in recent years. The sodium-glucose cotransporter 2 (SGLT-2) inhibitor empagliflozin and glucagon-like peptide 1 (GLP-1) agonist liraglutide are two rising stars in DKD treatment. There were 2 articles on empagliflozin among the top 100 most cited articles, one clinical trial (article number 36, 324 citations) published in 2013 and one experimental study (article number 96, 219 citations) published in

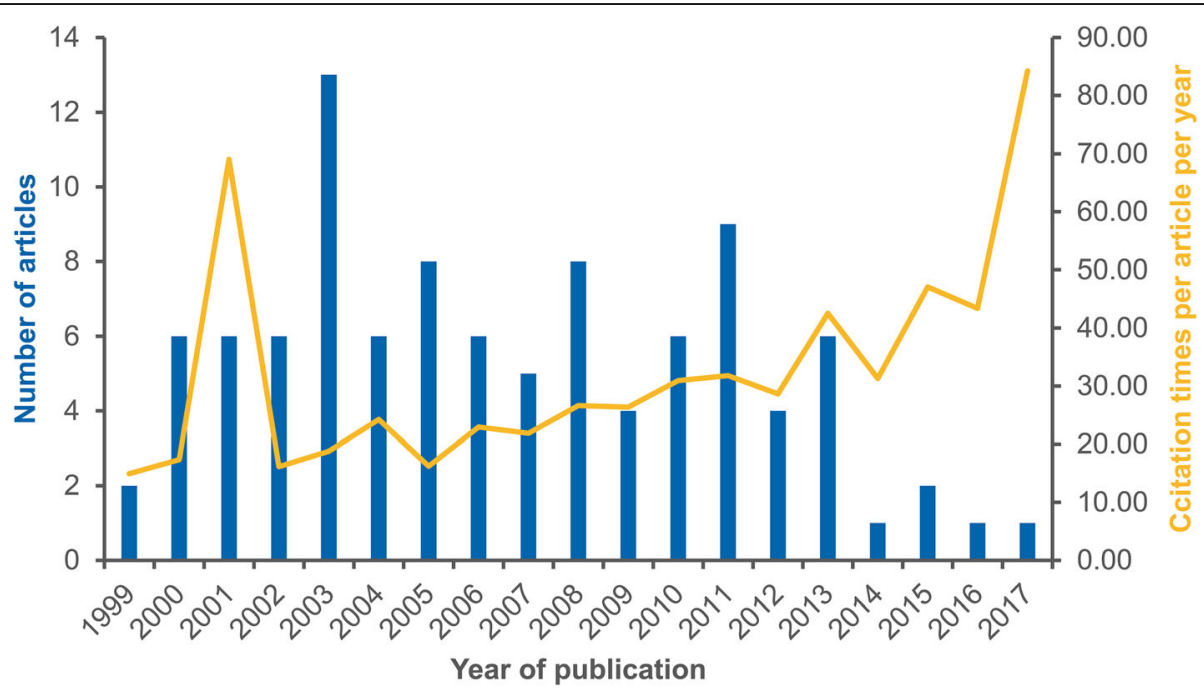

Fig. 2 Timespans of the top 100 most cited articles. The blue bars represent the number of publications for each year, and the yellow line represents the number of citations per article per year. The distributions of articles and citation in disparate years are shown in the figure 
Table 2 List of the relevant countries analysed according to the corresponding author

\begin{tabular}{llll}
\hline Country & $\begin{array}{l}\text { Number of } \\
\text { articles }\end{array}$ & $\begin{array}{l}\text { Single-county } \\
\text { publication }\end{array}$ & $\begin{array}{l}\text { Multiple-country } \\
\text { publication }\end{array}$ \\
\hline USA & 47 & 24 & 23 \\
Japan & 14 & 8 & 6 \\
Australia & 11 & 6 & 5 \\
Germany & 5 & 1 & 4 \\
Netherland & 5 & 0 & 5 \\
Denmark & 4 & 0 & 4 \\
UK & 3 & 2 & 1 \\
Canada & 2 & 0 & 2 \\
Finland & 2 & 0 & 2 \\
Belgium & 1 & 0 & 1 \\
Chile & 1 & 0 & 1 \\
China & 1 & 1 & 0 \\
India & 1 & 1 & 0 \\
Ireland & 1 & 0 & 1 \\
Italy & 1 & 0 & 1 \\
Korea & 1 & 0 & 1 \\
\hline & & &
\end{tabular}

2014. Moreover, the clinical trial of liraglutide published in 2017 (article number 32, 337 citations) was the latest among the 100 articles. These new drugs represent new trends in DKD research.

Some experimental studies uncovered the crucial mechanisms of DKD, but the clinical translations of these studies were not included in the top 100 most cited articles. Fifteen articles elucidated the important roles of podocyte dysfunction (article number 33, 37, 54, 59,77 , and 87, a total of 1637 citations), immune cells and inflammation (article number 31, 43, 53, 68, 79, and 90, a total of 1616 citations), and vascular endothelial growth factor (VEGF) (article number 23, 28, 74, totally cited 943 times) in DKD, and 4 articles that were cited 1858 times demonstrated that transforming growth factor (TGF)- $\beta$ (article number 6), fibroblasts (article number 12), and connective tissue growth factor (CTGF) (article number 40,42) contribute to renal fibrosis in DKD. A new mechanism drawing the attention of researchers was the role of microRNAs (miRs) in DKD, which was discussed in 8 articles published from 2007 to 2013 (article number 13, 20, 34, 48, 57, 78, 83, and 99, a total of 2503 citations). Furthermore, metabolomics and transcriptomics analyses deepened researchers' understanding of DKD. Targeting metabolic alterations (article number $29,56,65$, and 82 , a total of 1085 citations) and novel transcription factors (TFs) (article number 49, 61, 69 , and 94, a total of 998 citations) had therapeutic effects in experimental DKD.

The articles above revealed the mechanism of and treatment strategies for DKD. In the remaining clinical studies, one article (article number 8, 571 citations) emphasized the importance of blood pressure (BP) control in DKD, and 2 articles discussed microalbuminuria (article number 14, 66, a total of 744 citations) in T1DM. Figure $4 \mathrm{~d}$ and e show the distributions of topics in 'CS' and 'MG' articles respectively. Furthermore, in Table 5, we separately list the information and results of clinical studies in regard to their critical roles in clinical guidance.

Regarding other article types, 9 articles subcategorized as 'ES' and 'PP' helped researchers understand DKD from disparate aspects. Seven articles (article number 4, $16,26,46,58,76$, and 99 , a total of 2603 citations) were based on the epidemiological aspects of DKD, and 2 articles (article number 11, 47, a total of 828 citations) defined the pathological characteristics and classifications of DKD. Four of the 9 articles (article number 4, 26, 47, and 58) were specifically on nephropathy in T1DM.

\section{Evolution of topics in clinical and experimental studies of DKD}

To elucidate the trends in DKD research, we analysed the distributions of topics of 'CS' and 'MG' articles in different periods and illustrated their evolution, as

Table 3 Subcategories of the top 100 most cited articles

\begin{tabular}{|c|c|c|c|c|}
\hline Subcategory & Description & Article Number & $\begin{array}{l}\mathrm{CT} \\
\text { (total) }\end{array}$ & $\begin{array}{l}\% \\
\text { total }\end{array}$ \\
\hline $\begin{array}{l}\text { Experimental studies } \\
\text { (EG) } \\
n=65\end{array}$ & $\begin{array}{l}\text { Studies on mechanisms, metabolomics, } \\
\text { transcriptome, genetics, potential molecular } \\
\text { biomarkers }\end{array}$ & $\begin{array}{l}5,6,12,13,19-25,28-31,33,34,37-40,42,43,45,48,49,51 \\
53-57,59-61,63,65,67-74,77-79,81-85,87-92,94-97,99 \\
100\end{array}$ & 19,280 & 49.62 \\
\hline $\begin{array}{l}\text { Clinical studies (CS) } \\
n=26\end{array}$ & Clinical trials, observational studies & $\begin{array}{l}1-3,7-10,14,15,17,18,27,32,35,36,41,44,50,52,62,64 \\
66,75,80,86,93\end{array}$ & 16,144 & 41.55 \\
\hline $\begin{array}{l}\text { Epidemiological studies } \\
\text { (ES) } \\
n=7\end{array}$ & Studies on prevalence, risk factors, outcomes & $4,16,26,46,58,76,98$ & 2603 & 6.70 \\
\hline $\begin{array}{l}\text { Pathological and } \\
\text { pathophysiological } \\
\text { studies (PP) } \\
n=2\end{array}$ & Studies on pathology and pathophysiology & 11,47 & 828 & 2.13 \\
\hline
\end{tabular}




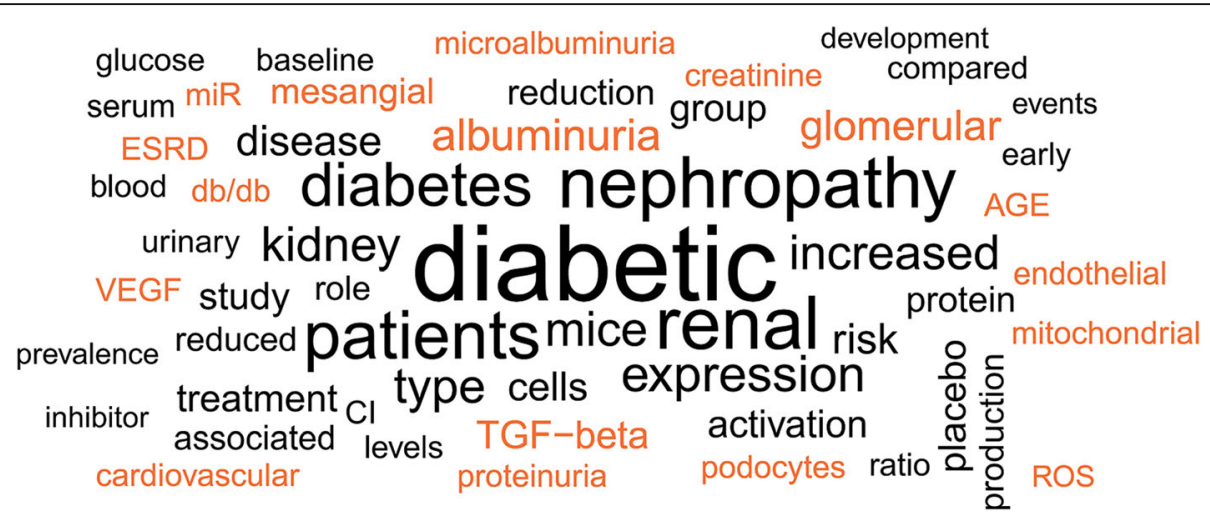

Fig. 3 Word cloud of the top 100 most cited articles. Key words were extracted from the abstracts of the top 100 most cited articles to illustrate a word cloud

shown in Figure S2. Interestingly, we found that RAAS and OS are continuous hotspots of DKD research, again emphasizing the significance of the two research fields. Although attention has been given in the past, the number of studies on AGEs and RAGE has declined in recent years, which may be due to the frustration of clinical translation. Articles on miRs were predominately concentrated from 2008 to 2012, indicating the trendy miRrelated study outbreak and attraction of numerous researchers in those years. In addition, some topics have appeared in recent years, including SGLT-2 and GLP-1, which have become new hotspots and have led to novel breakthroughs in DKD studies.

\section{Discussion}

In this study, we ranked the top 100 most cited articles on DKD according to the total number of citations in the Web of Science Core Collection. In addition, we analysed the journals, timespans, authors, countries and topics of the 100 articles. This bibliometric analysis helps readers quickly understand the influential studies in DKD research, which topics attract other researchers, and the evolution of the research trend, thus guiding researchers to find interesting research directions and may help facilitate international collaborations. Popular clinical studies guide readers in clinical practice to provide more benefits for patients. Important experimental studies provide laboratory evidence for clinical trials and deepen the comprehension of the development and progression of DKD. Although some studies have not yet been clinically translated, they may direct future research and provide potential biomarkers and therapeutic targets as the subject develops in the future.

Bibliometric analysis is an effective method that is utilized in diverse areas of study [12-16, 18-20]. A bibliometric analysis performed in 2019 [19] showed that 3 of the top 10 most cited articles in nephrology were on the subject of RAAS blockade usage in DKD. A former bibliometric analysis of DKD [20] highlighted the authors and co-citation networks but not the subcategories or contents. In this study, we further performed a bibliometric analysis of the top 100 most cited articles to elucidate what has been done and what needs to be completed in DKD research. In addition, there were some limitations in this study. We performed this study based on data from the Web of Science Core Collection, which means that some high-quality articles that were published earlier or were not in English were potentially excluded from this study. Another limitation is that the drawback of the bibliometric citation analysis method may contain bias, as recent articles have less time to be cited. Thus, we also listed the number of citations for each article per year, which helps to highlight the influence of recent studies [21] in addition to the total number of citations. On the other hand, we discussed the recent advances in traditional topics and more findings in the latest hotspots.

The most relevant field and a persistent interest in DKD research is RAAS, which was associated with most articles and citations. In the latest Kidney Disease: Improving Global Outcomes guidelines [1], angiotensinconverting enzyme inhibitors (ACEis) and angiotensin-II receptor blockers (ARBs) are recommended for use in DKD patients. In addition to ACEis and ARBs, there are other types of RAAS blockades, including direct renin inhibitors and ectoenzyme neutral endopeptidase inhibitors. In 2008, a randomized study showed that the combination of losartan and aliskiren, a direct renin inhibitor, significantly reduced the mean urine albuminto-creatinine ratio (UACR) compared with that achieved with losartan combined with placebo in T2DM patients (article number 3, 751 citations). In 2018, the intentionto-treat analysis of UK HARP-III [22] showed that sacubitril, an ectoenzyme neutral endopeptidase inhibitor, combined with valsartan had a similar renal benefit and additional heart function protection when compared to 


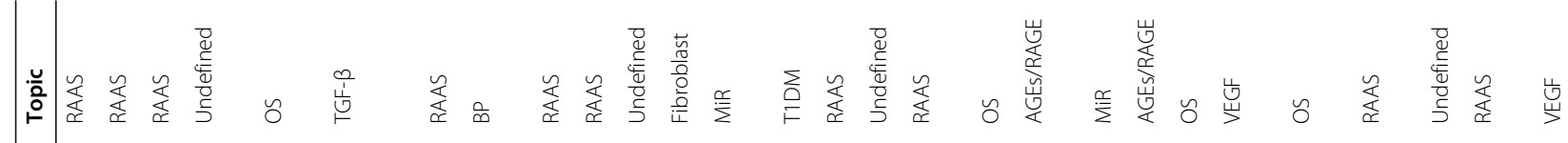

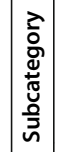

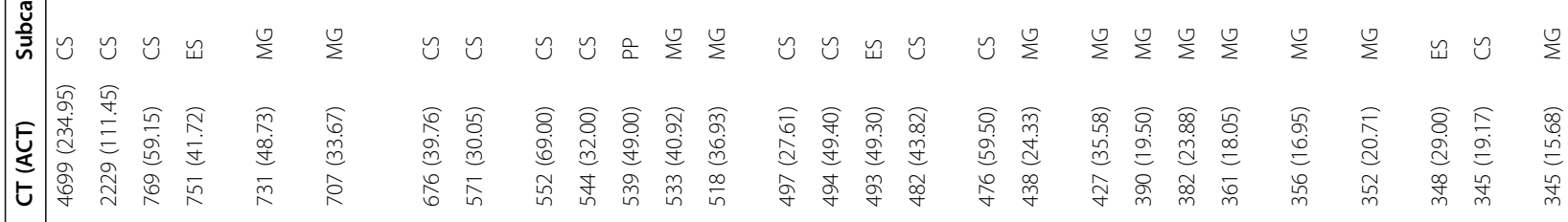

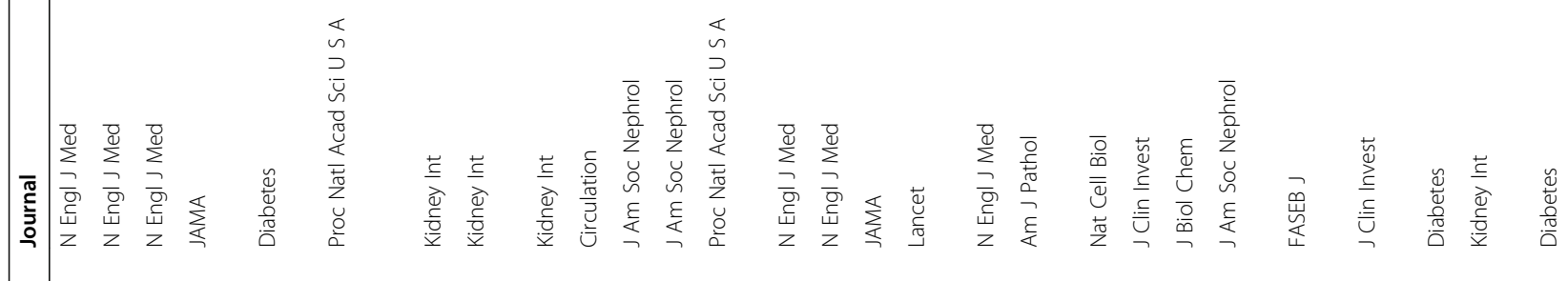

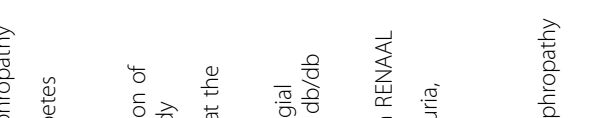

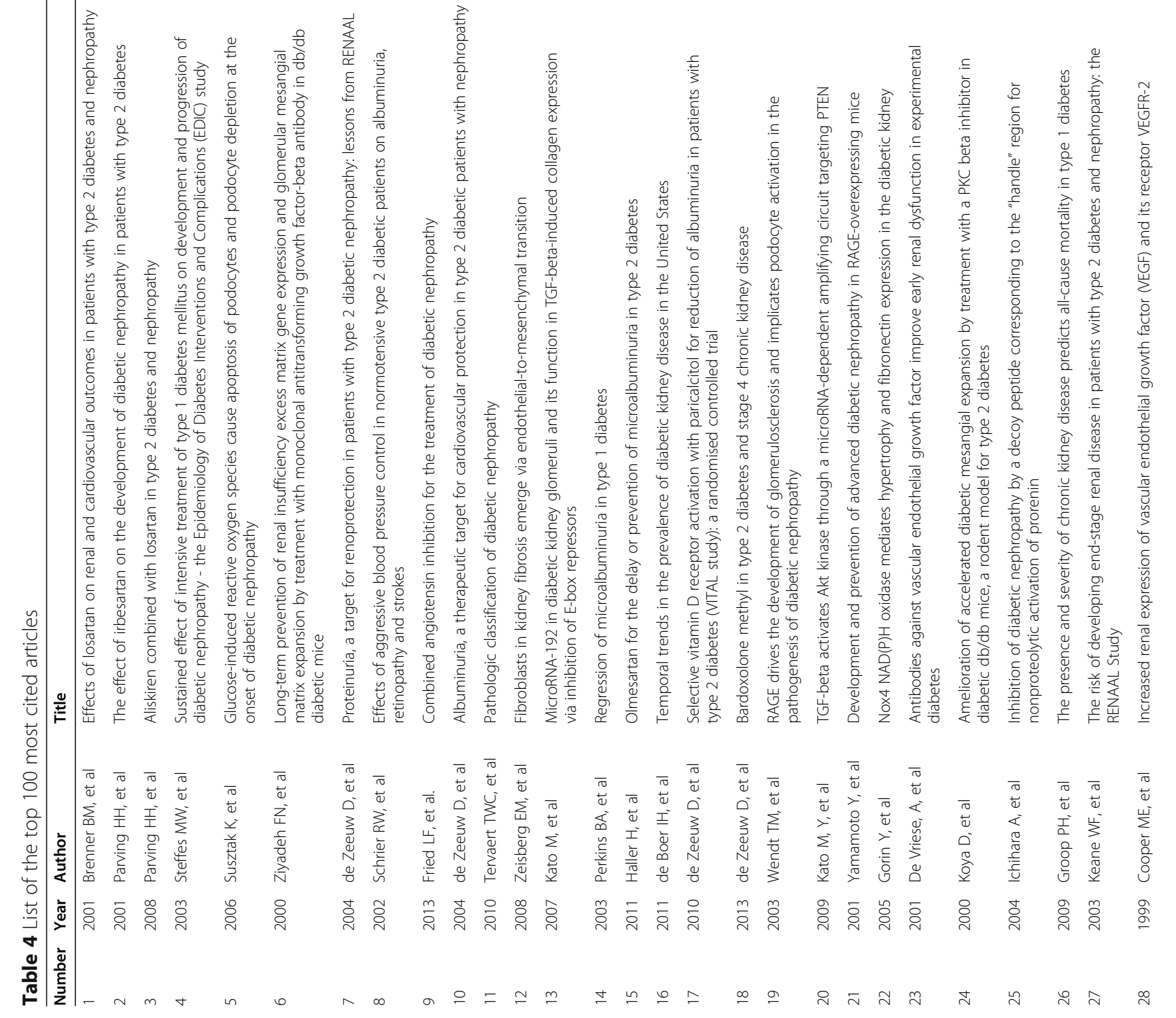




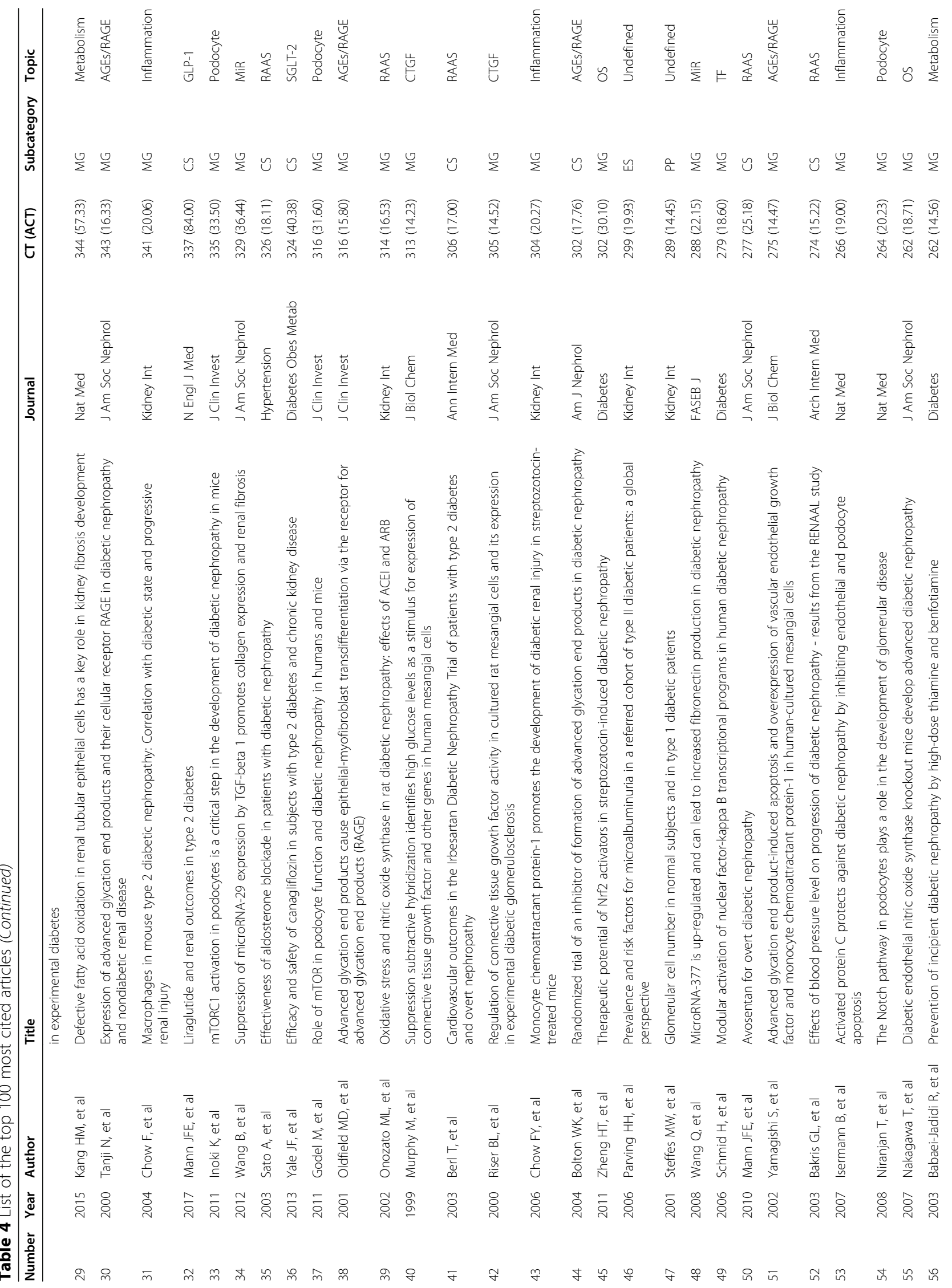




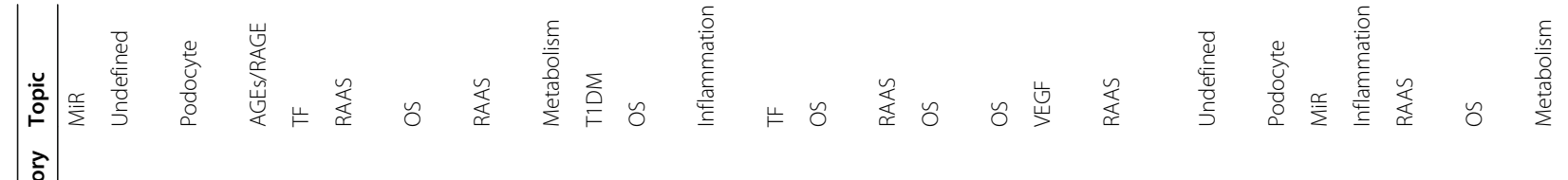

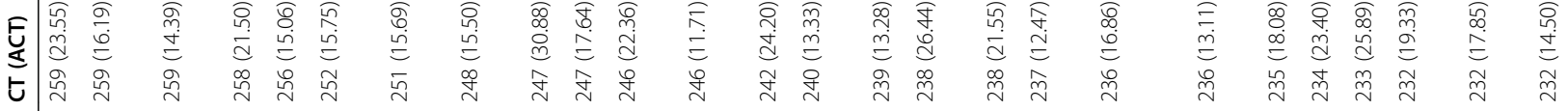

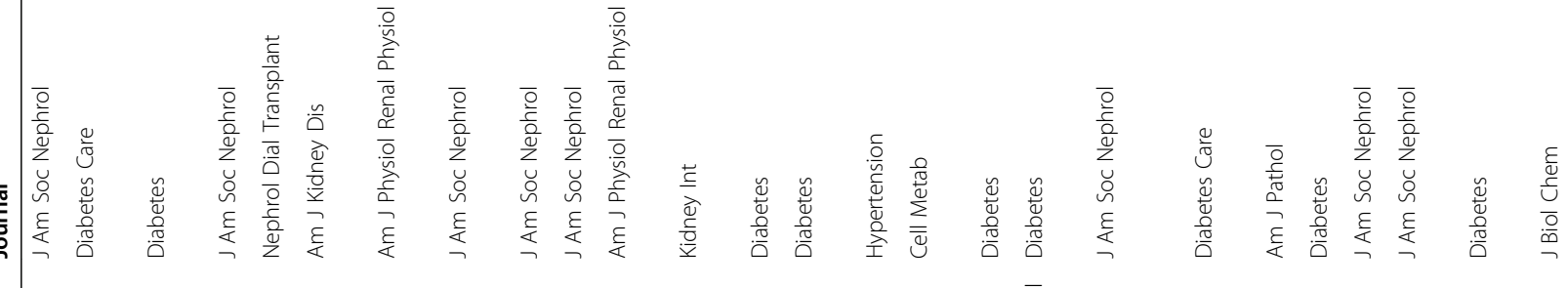

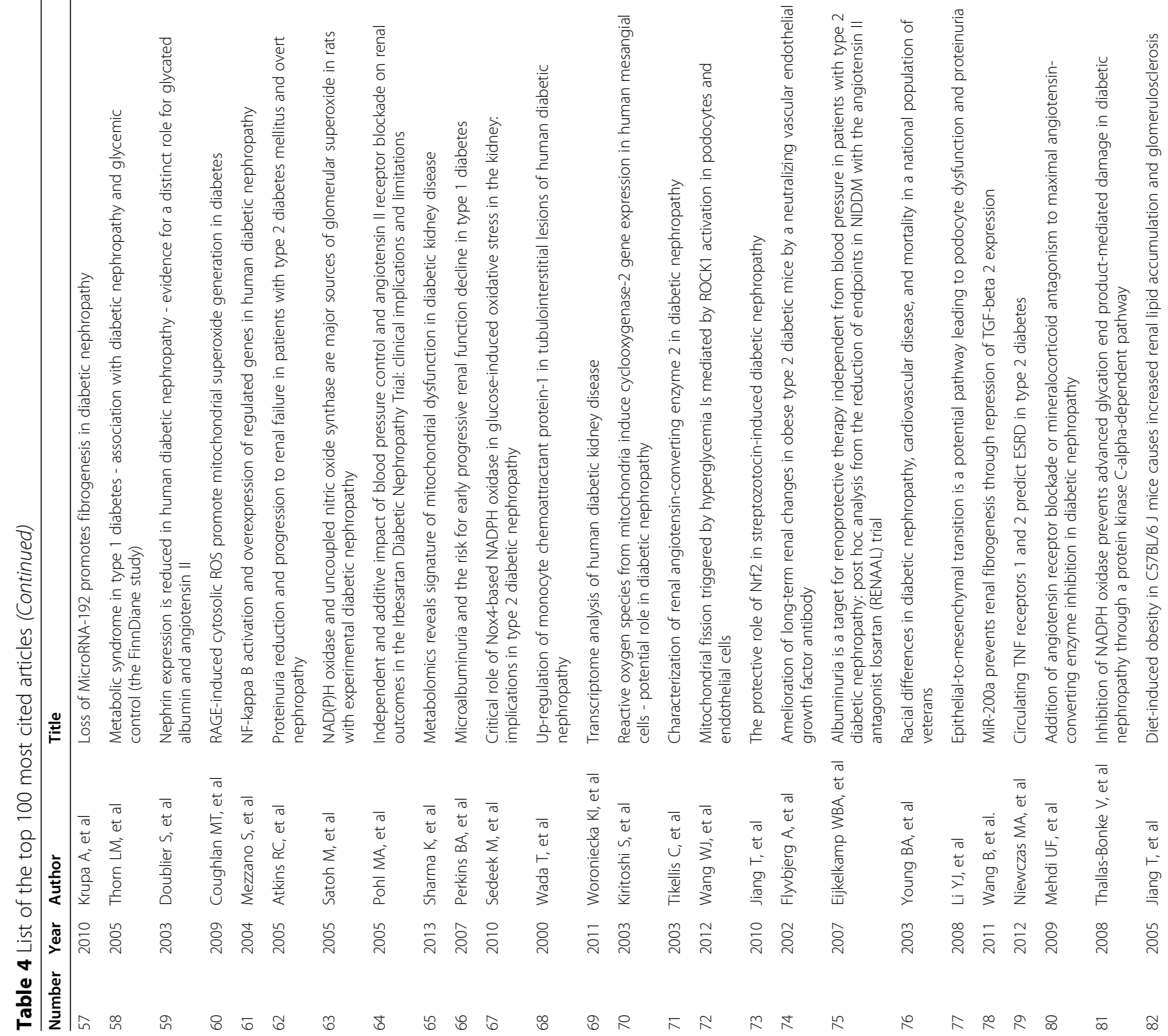




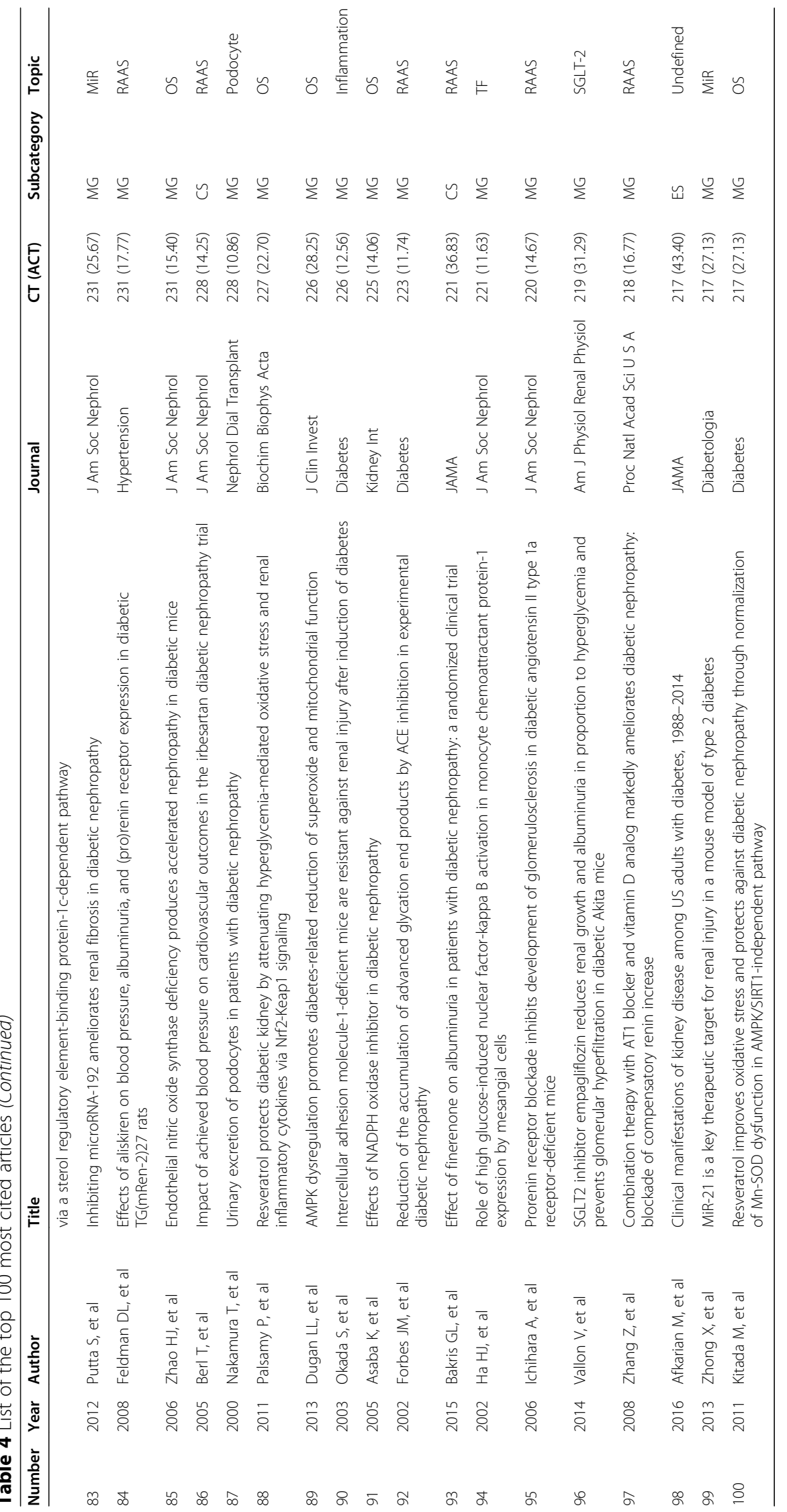




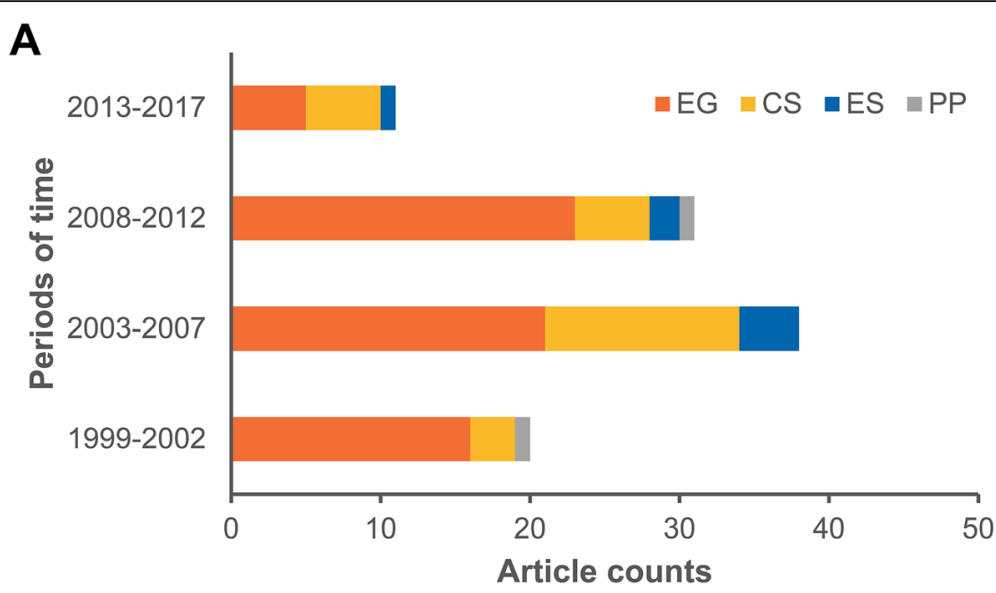

B

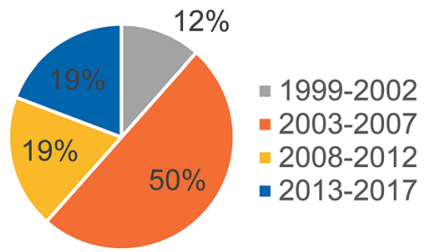

D

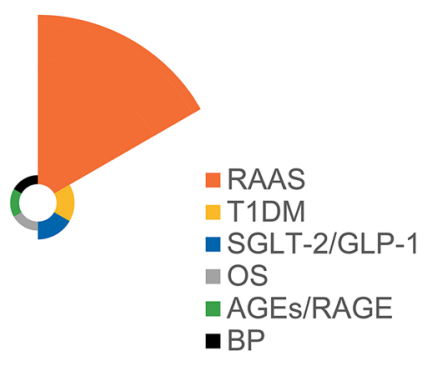

C

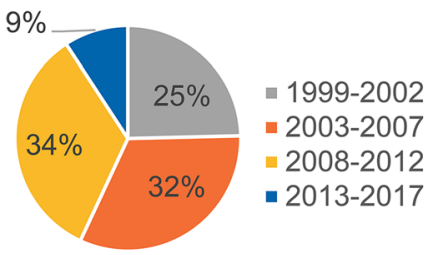

E

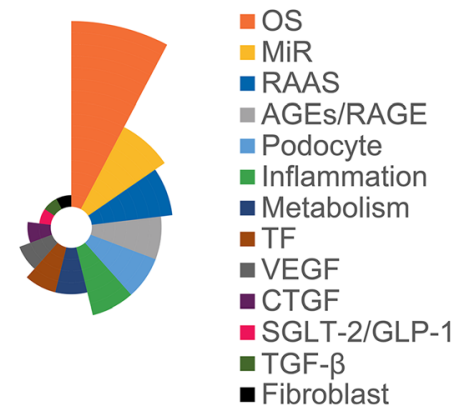

Fig. 4 Distributions of the subcategories, topics and time periods. The distributions of the 100 articles are shown in the figure (a). The distributions of clinical studies (b) and experimental studies (c) in different time periods are shown as pie charts. The distributions of topics in clinical (d) and experimental studies (e) are showed as Nightingale rose charts

that achieved with irbesartan in patients with an estimated glomerular filtration rate of 60 to $20 \mathrm{~mL} / \mathrm{min} /$ $1.73 \mathrm{~m}^{2}$. The intention-to-treat analysis of PARADIGMHF [23] showed that sacubitril combined with valsartan took advantage of delaying renal function decline and protecting heart function when compared with enalapril in patients with diabetes. Novel RAAS inhibitors have promising prospects in the treatment of DKD owing to their advantages.

Notably, article number 71 (239 citations) highlights the expression of angiotensin-converting enzyme 2 (ACE2) in DKD. However, the expression of ACE2 in DKD is controversial [24, 25]. One recent study [26] found that the mRNA level of ACE2 was increased in the proximal tubular epithelial cells of DKD patients. In addition, some studies [27, 28] have shown that RAAS inhibitors upregulate the expression of ACE2. ACE2 is the receptor for SARS-CoV-2 [29-31], which is responsible for the COVID-19 outbreak, giving rise to the following two questions: will renal injury be increased in COVID-19 patients with diabetes and will ACEi/ARB treatment have an impact on the renal outcome of COVID-19 patients with diabetes? COVID-19 patients with T2DM have higher acute kidney injury prevalence rates than individuals without diabetes [32], which may be explained by ACE2-mediated viral cytopathic effects $[26,33]$. Some studies $[34,35]$ implied that RAAS inhibitors increased the risk of acute kidney injury, suggesting more concern about renal outcomes in patients with severe COVID-19 with diabetes who are treated with 
Table 5 List of the clinical studies among the top 100 most cited articles

\begin{tabular}{lll}
\hline Information & Topic & Patients \\
\hline Article number 1: Effects of losartan on renal and & RAAS & T2DM patients with \\
cardiovascular outcomes in patients with type 2 & & nephropathy \\
diabetes and nephropathy & & \\
ACT: 234.95 &
\end{tabular}

\section{Main results}

Losartan reduced the incidence of a doubling of the serum creatinine concentration, the incidence of endstage renal disease, and the level of proteinuria by 25 , 28 , and $35 \%$, respectively. In addition, losartan did not significantly alter the morbidity and mortality from cardiovascular causes.

Article number 2: The effect of irbesartan on the development of diabetic nephropathy in patients with type 2 diabetes

ACT: 111.45

Article number 3: Aliskiren combined with losartan in type 2 diabetes and nephropathy ACT: 59.15

Article number 7: Proteinuria, a target for renoprotection in patients with type 2 diabetic nephropathy: lessons from RENAAL

ACT: 39.76

Article number 8: Effects of aggressive blood pressure control in normotensive type 2 diabetic patients on albuminuria, retinopathy and strokes ACT: 30.05

Article number 9: Combined angiotensin inhibition for the treatment of diabetic nephropathy ACT: 69.00

Article number 10: Albuminuria, a therapeutic target for cardiovascular protection in type 2 diabetic patients with nephropathy

ACT: 32.00

Article number 14: Regression of microalbuminuria in type 1 diabetes

ACT: 27.61

Article number 15: Olmesartan for the delay or prevention of microalbuminuria in type 2 diabetes ACT: 49.40

Article number 17: Selective vitamin D receptor activation with paricalcitol for reduction of albuminuria in patients with type 2 diabetes (VITAL study): a randomised controlled trial

ACT: 43.82

Article number 18: Bardoxolone methyl in type 2 diabetes and stage 4 chronic kidney disease ACT: 59.50

Article number 27: The risk of developing end-stage renal disease in patients with type 2 diabetes and nephropathy: The RENAAL Study

ACT: 19.17
RAAS Hypertensive patients with T2DM and microalbuminuria

RAAS Hypertensive patients with T2DM and nephropathy

RAAS T2DM patients with nephropathy

BP Normotensive T2DM patients

RAAS T2DM veterans with overt nephropathy

RAAS T2DM patients with nephropathy

T1DM T1DM patients with microalbuminuria

RAAS T2DM patients

RAAS T2DM patients with albuminuria and ACEi or ARB treatment

OS T2DM patients with stage 4 chronic kidney disease

RAAS T2DM patients with nephropathy
Irbesartan reduced the incidence of nephropathy and the level of urinary albumin excretion independently of its antihypertensive effect. In addition, irbesartan also reduced the incidence of serious adverse events.

Aliskiren reduced the mean UACR by $20 \%$ without significant change in the total numbers of adverse and serious adverse events.

Baseline albuminuria was the predominant renal risk parameter. The residual albuminuria after 6 months of losartan treatment was another strong renal risk parameter. Losartan reduced the level of albuminuria, which was the major explanation of its renoprotective function.

Over a 5-year follow-up period, intensive BP control (approximately 128/75 $\mathrm{mmHg}$ ) reduced the percentage of normoalbuminuria-to-microalbuminuria and microalbuminuria-to-overt albuminuria, the progression of diabetic retinopathy and the incidence of stroke compared to the moderate BP control group (approximately 137/81 mmHg). In addition, intensive BP control had no significant influence on creatinine clearance.

Over a 2-year follow-up period, the combination of ACEi and ARB induced hyperkalemia and acute kidney injury.

For safety concerns, the study was stopped.

Baseline albuminuria was the predominant risk predictor of cardiovascular outcome. Reducing albuminuria in the first 6 months was renoprotective.

Over a 6-year follow-up period, the incidence of regression of microalbuminuria was 58\%. The regression of microalbuminuria did not indicate inexorable progression of nephropathy, and ACEi treatment was not associated with the regression of microalbuminuria.

Over a 3-year follow-up period, olmesartan delayed the onset of microalbuminuria by $23 \%$. Notably, olmesartan increased the risk of fatal cardiovascular events among T2DM patients with preexisting coronary heart disease.

Addition of $2 \mu \mathrm{g} /$ day paricalcitol to RAAS inhibition safely reduced UACR by 18 to $28 \%$ compared with placebo.

Over a 9-month follow-up period, bardoxolone methyl did not reduce the risk of end-stage renal disease or death from cardiovascular causes but induced cardiovascular events.

For safety concerns, the study was stopped.

A multivariate model showed that proteinuria, serum creatinine, serum albumin and haemoglobin level were independent risk predictors of renal outcomes after control of BP. Moreover, the level of proteinuria was the most important risk parameter for progressive kidney injury. 
Table 5 List of the clinical studies among the top 100 most cited articles (Continued)

\begin{tabular}{|c|c|c|}
\hline Information & Topic & Patients \\
\hline $\begin{array}{l}\text { Article number 32: Liraglutide and renal outcomes } \\
\text { in type } 2 \text { diabetes } \\
\text { ACT: } 84.00\end{array}$ & GLP-1 & $\begin{array}{l}\text { T2DM patients with high risk } \\
\text { for cardiovascular disease }\end{array}$ \\
\hline $\begin{array}{l}\text { Article number 35: Effectiveness of aldosterone } \\
\text { blockade in patients with diabetic nephropathy } \\
\text { ACT: } 18.11\end{array}$ & RAAS & $\begin{array}{l}\text { T2DM patients with early } \\
\text { nephropathy and ACEi } \\
\text { treatment }\end{array}$ \\
\hline $\begin{array}{l}\text { Article number 36: Efficacy and safety of } \\
\text { canagliflozin in subjects with type } 2 \text { diabetes and }\end{array}$ & $\begin{array}{l}\text { SGLT- } \\
2\end{array}$ & $\begin{array}{l}\text { T2DM patients with stage } 3 \\
\text { chronic kidney disease }\end{array}$ \\
\hline
\end{tabular}
chronic kidney disease

ACT: 40.38

ACT: 15.75 diabetes
Article number 41: Cardiovascular outcomes in the Irbesartan Diabetic Nephropathy Trial of patients with type 2 diabetes and overt nephropathy

ACT: 17.00

Article number 44: Randomized trial of an inhibitor of formation of advanced glycation end products in diabetic nephropathy

ACT: 17.76

Article number 50: Avosentan for overt diabetic nephropathy

ACT: 25.18

Article number 52: Effects of blood pressure level on progression of diabetic nephropathy - results from the RENAAL study

\section{ACT: 15.22}

Article number 62: Proteinuria reduction and progression to renal failure in patients with type 2 diabetes mellitus and overt nephropathy

Article number 64: Independent and additive impact of blood pressure control and angiotensin II receptor blockade on renal outcomes in the Irbesartan Diabetic Nephropathy Trial: clinical implications and limitations

ACT: 15.50

Article number 66: Microalbuminuria and the risk for early progressive renal function decline in type 1

ACT: 17.64

RAAS T2DM patients with overt nephropathy

AGEs/ T1DM patients with

RAGE nephropathy and retinopathy

OS T2DM patients with ACEi or ARB treatment

RAAS T2DM patients with nephropathy and hypertension

RAAS T2DM patients with overt nephropathy

RAAS Hypertensive T2DM patients with overt nephropathy

T1DM T1DM patients

RAAS T2DM patients with hypertension renoprotective therapy independent from blood pressure in patients with type 2 diabetic nephropathy: post hoc analysis from the reduction of endpoints in NIDDM with the angiotensin II antagonist losartan (RENAAL) trial

ACT: 16.86

Article number 80: Addition of angiotensin receptor

RAAS Hypertensive T2DM patients

\section{Main results}

Over a 3-year follow-up period, liraglutide reduced the new onset of persistent macroalbuminuria by $26 \%$ and the risk of the development and progression of DKD.

Aldosterone escape appeared in $40 \%$ of patients and led to less effective antiproteinuric effects of ACE treatment. Over a 6-month follow-up period, addition of spironolactone to ACEi reduced UACR and left ventricular mass index while it did not significantly influence BP.

Canagliflozin reduced $\mathrm{HbA} 1 \mathrm{c}$ and fasting plasma glucose and was generally well tolerated.

Irbesartan or amlodipine in addition to conventional antihypertensive therapy did not significantly influence the risk of composite cardiovascular events compared to placebo in addition to conventional antihypertensive therapy.

Pimagedine did not significantly influence the progression of overt nephropathy.

Over a 4-month follow-up period, addition of avosentan to RAAS inhibitor reduced albuminuria but induced significant fluid overload and congestive heart failure.

For safety concerns, the study was stopped.

Baseline systolic blood pressure was a stronger risk predictor than diastolic blood pressure of renal outcomes. Patients with the highest baseline pulse pressure had the highest renal risk and benefited most after losartan-reduced systolic blood pressure.

Each doubling of baseline proteinuria level doubled the risk for renal failure. Each halving of proteinuria level between baseline and 12 months with treatment reduced the risk for renal failure by $56 \%$. With the same reduction in proteinuria, irbesartan reduced more risk of renal failure compared to amlodipine.

Systolic blood pressure was the strong risk predictor of baseline serum creatinine doubling or end-stage renal disease. Systolic blood pressure target between 120 and $130 \mathrm{mmHg}$ combined with irbesartan was recommended.

There was no correlation between diastolic blood pressure and renal outcomes.

Early renal function decline occurred in $9 \%$ of the normoalbuminuria group and $31 \%$ of the microalbuminuria group. In multivariate analysis, the risk of early renal function decline increased after 35 years old or $\mathrm{HbA} 1 \mathrm{c}$ exceeding $9 \%$ but was not influenced by diabetes duration, smoking, BP or ACEi treatment. Cystatin $C$ together with microalbuminuria was recommended to diagnose early renal function decline.

Systolic blood pressure reduction, albuminuria regression and low level of residual albuminuria were associated with a lower risk of end-stage renal disease. Systolic blood pressure reduction together with albuminuria regression was recommended to be the target of antihypertensive treatment to improve renal outcome. 
Table 5 List of the clinical studies among the top 100 most cited articles (Continued)

\begin{tabular}{|c|c|c|c|}
\hline Information & Topic & Patients & Main results \\
\hline $\begin{array}{l}\text { blockade or mineralocorticoid antagonism to } \\
\text { maximal angiotensin-converting enzyme inhibition in } \\
\text { diabetic nephropathy } \\
\text { ACT: } 19.33\end{array}$ & & with albuminuria & $\begin{array}{l}\text { spironolactone to lisinopril reduced UACR by } 36 \% \text { and } \\
\text { addition of losartan to lisinopril reduced UACR by } \\
16.8 \% \text {. Spironolactone was recommended to be } \\
\text { combined with lisinopril for a greater renoprotective } \\
\text { function in addition to BP control. }\end{array}$ \\
\hline $\begin{array}{l}\text { Article number 86: Impact of achieved blood } \\
\text { pressure on cardiovascular outcomes in the irbesartan } \\
\text { diabetic nephropathy trial } \\
\text { ACT: } 14.25\end{array}$ & RAAS & $\begin{array}{l}\text { T2DM patients with overt } \\
\text { nephropathy }\end{array}$ & $\begin{array}{l}\text { Progressively lower achieved BP 120/85 mmHg was } \\
\text { associated with the best protection against } \\
\text { cardiovascular events. Increased pulse pressure, systolic } \\
\text { blood pressure below } 120 \mathrm{mmHg} \text { or diastolic blood } \\
\text { pressure below } 85 \mathrm{mmHg} \text { was associated with } \\
\text { increased cardiovascular events. }\end{array}$ \\
\hline $\begin{array}{l}\text { Article number 93: Effect of finerenone on } \\
\text { albuminuria in patients with diabetic nephropathy: a } \\
\text { randomized clinical trial } \\
\text { ACT: } 36.83\end{array}$ & RAAS & $\begin{array}{l}\text { Diabetic patients with high } \\
\text { or very high albuminuria and } \\
\text { ACEi or ARB treatment }\end{array}$ & $\begin{array}{l}\text { Addition of finerenone to ACEi or ARB dose- } \\
\text { dependently reduced UACR and was well tolerated. }\end{array}$ \\
\hline
\end{tabular}

ACEis/ARBs. More studies are needed to further elucidate the roles of ACE2 and ACEi/ARB-induced ACE2 in DKD.

Strategies for protecting renal function are a permanent topic of DKD. Although RAAS blockade benefits a substantial population of patients, there are still some questions regarding DKD treatment. Unfortunately, the development of novel drugs based on new mechanisms in DKD treatment has been uneven. Fortunately, two novel types of drugs, SGLT-2 inhibitors and GLP-1 receptor agonists, may represent the future of DKD treatment methods. CREDENCE [36] and the following analysis of CREDENCE $[37,38]$ revealed that canagliflozin reduces the risk of renal failure and cardiovascular events and decreases anaemia-associated outcomes in T2DM patients with kidney disease. DAPA-CKD [39] showed that dapagliflozin, another SGLT-2 inhibitor, reduces kidney and cardiovascular events in chronic kidney disease patients with and without T2DM. Intriguingly, the latest publication among the top 100 most cited articles is a clinical trial of another new drug, liraglutide, a GLP-1 receptor agonists (article number 32), which has been proven to reduce the occurrence of persistent macroalbuminuria. Encouragingly, the two novel types of agents showed more advantages for kidney function protection than dipeptidyl peptidase-4 inhibitor or sulfonylureas [40] and were recommended by the Kidney Disease: Improving Global Outcomes guidelines guidelines [1] and consensus report by American Diabetes Association and the European Association for the study of diabetes $[41,42]$ in T2DM patients with chronic kidney disease. To develop more novel targets of DKD treatment, further comprehension of the mechanisms of DKD is indispensable.

Technological innovation promotes scientific development. High-throughput technology and multiomics studies help researchers further understand the pathogenesis and prognosis of DKD (article number 65, 69). The application of single-cell and single-nucleus transcriptomics [43-45] identifies novel types of cells, describes cell-to-cell crosstalk, discovers further mechanisms and provides new insight into renal diseases. Further understanding the disease will help researchers find potential biomarkers and novel therapeutic strategies in the future.

Moreover, artificial intelligence is widely applied in the analysis of clinical indicators, digital imaging data, and digital pathological data in renal diseases [46, 47] and improves the diagnosis and prognostication of DKD [48-50]. High-performance models built by artificial intelligence may contribute to more effective and accurate interventions in the clinical practice of DKD.

\section{Conclusion}

In conclusion, this article focused on the top 100 most cited articles on the subject of DKD. By reviewing the popular studies over several decades, researchers can better understand the evolution of DKD research. The important roles of ACEis and ARBs were once again emphasized in this study, and the prospects of SGLT-2 inhibitors and GLP-1 receptor activators are promising. Influential studies deepen the understanding of DKD and provide evidence for novel biomarkers and potential therapeutic strategies. This study helps readers quickly understand the important studies on DKD research, the distribution of popular topics and the evolution of the subject, thus providing a guide for research direction, international collaboration and clinical practice to better server patients.

\section{Abbreviations}

DM: Diabetic mellitus; DKD: Diabetic kidney disease; CKD: Chronic kidney disease; OS: Oxidative stress; CT: Citation time; ACT: Average citation time; EG: Experimental studies; CS: Clinical studies; ES: Epidemiological studies; PP: Pathological and pathophysiological studies; RAAS: Renin-angiotensinaldosterone system; ROS: Reactive oxygen species; AGEs: Advanced glycation end products; RAGE: Receptor for advanced glycation end products;

T1DM: Type 1 diabetic mellitus; SGLT-2: Sodium-glucose cotransporter 2; GLP-1: Glucagon-like peptide 1; VEGF: Vascular endothelial growth factor; 
TGF: Transforming growth factor; CTGF: Connective tissue growth factor; miR: MicroRNA; TF: Transcriptional factor; BP: Blood pressure; T2DM: Type 2 diabetic mellitus; ACEi: Angiotensin-converting enzyme inhibitors; ARB: Angiotensin-II receptor blockers; UACR: Urine albumin-to-creatinine ratio; ACE2: Angiotensin-converting enzyme 2

\section{Supplementary Information}

The online version contains supplementary material available at https://doi. org/10.1186/s12882-021-02369-z.

Additional file 1: Figure S1. The top 10 relevant authors who contributed to the top 100 most cited articles. The dot size represents the author's score, and the dot colour reflets the number of articles. Black represents one article, blue represents two articles, yellow represents three articles, and orange represents four articles. The authors' contributions are exhibited as a bubble plot.

Additional file 2: Figure S2. The evolution of topics in DKD research. The distributions of the topics RAAS (A), OS (B), AGEs and RAGE (C), miR (D), podocyte (E), inflammation (F), metabolism $(G)$, TF $(H)$, SGLT-2 and GLP-1 (I), VEGF (J), T1DM (K), CTCF (L), TGF- $\beta(M)$, fibroblast (N) and BP $(\mathrm{O})$ in different time periods reflect the evolution of topics in DKD research.

Additional file 3: Table S1. Recent reviews on the subject of DKD.

\section{Acknowledgements}

Not applicable.

\section{Authors' contributions}

Yi Wei designed the study and drafted the paper, and Zongpei Jiang revised the paper.

\section{Funding}

Not applicable.

\section{Availability of data and materials}

All data generated or analysed during this study are included in this published article [and its supplementary information files].

\section{Declarations}

Ethics approval and consent to participate

Not applicable.

\section{Consent for publication}

Not applicable.

\section{Competing interests}

The authors declare that they have no competing interests.

Received: 26 November 2020 Accepted: 20 April 2021

Published online: 29 April 2021

\section{References}

1. Kidney Disease: Improving Global Outcomes (KDIGO) Diabetes Work Group. KDIGO 2020 clinical practice guideline for diabetes management in chronic kidney disease. Kidney Int. 2020;98(4S):S1-S115. https://doi.org/10.1016/j. kint.2020.06.019.

2. American Diabetes Association. Microvascular complications and foot care: standards of medical care in diabetes-2019. Diabetes Care. 2019;42(Suppl 1): S124-38. https://doi.org/10.2337/dc19-S011.

3. Donate-Correa J, Luis-Rodriguez D, Martin-Nunez E, Tagua VG, HernandezCarballo C, Ferri C, et al. Inflammatory targets in diabetic nephropathy. J Clin Med. 2020;9(2):458. https://doi.org/10.3390/jcm9020458.

4. Tang SCW, Yiu WH. Innate immunity in diabetic kidney disease. Nat Rev Nephrol. 2020;16(4):206-22. https://doi.org/10.1038/s41581-019-0234-4.

5. Yaribeygi $H$, Katsiki N, Butler AE, Sahebkar A. Effects of antidiabetic drugs on NLRP3 inflammasome activity, with a focus on diabetic kidneys. Drug Discov Today. 2019;24(1):256-62. https://doi.org/10.1016/j.drudis.2018.08.005.
6. Forbes JM, Thorburn DR. Mitochondrial dysfunction in diabetic kidney disease. Nat Rev Nephrol. 2018;14(5):291-312. https://doi.org/10.1038/ nrneph.2018.9.

7. Sifuentes-Franco S, Enrique Padilla-Tejeda D, Carrillo-lbarra S, Miranda-Diaz AG. Oxidative stress, apoptosis, and mitochondrial function in diabetic nephropathy. Int J Endocrinol. 2018:1875870. https://doi.org/10.1155/2018/1875870.

8. Sagoo MK, Gnudi L. Diabetic nephropathy: is there a role for oxidative stress? Free Radic Biol Med. 2018;116:50-63. https://doi.org/10.1016/j.freera dbiomed.2017.12.040.

9. Warren AM, Knudsen ST, Cooper ME. Diabetic nephropathy: an insight into molecular mechanisms and emerging therapies. Expert Opin Ther Tar. 2019; 23(7):579-91. https://doi.org/10.1080/14728222.2019.1624721.

10. Kato M, Natarajan R. Epigenetics and epigenomics in diabetic kidney disease and metabolic memory. Nat Rev Nephrol. 2019;15(6):327-45. https:// doi.org/10.1038/s41581-019-0135-6.

11. Vallon $V$, Thomson SC. The tubular hypothesis of nephron filtration and diabetic kidney disease. Nat Rev Nephrol. 2020;16(6):317-36. https://doi. org/10.1038/s41581-020-0256-y.

12. Stout NL, Alfano CM, Belter CW, Nitkin R, Cernich A, Lohmann SK, et al. A bibliometric analysis of the landscape of cancer rehabilitation research (19922016). J Natl Cancer Inst. 2018;110(8):815-24. https://doi.org/10.1093/jnci/djy108.

13. Schargus $M$, Kromer $R$, Druchkiv $V$, Frings $A$. The top 100 papers in dry eye a bibliometric analysis. Ocul Surf. 2018;16(1):180-90. https://doi.org/10.1016/ j.jtos.2017.09.006.

14. Chen X, Ding R, Xu K, Wang S, Hao T, Zhou Y. A bibliometric review of natural language processing empowered mobile computing. Wirel Commun Mob Comput. 2018:1827074. https://doi.org/10.1155/2018/1827074.

15. Chen X, Zhang X, Xie H, Tao X, Wang FL, Xie N, et al. A bibliometric and visual analysis of artificial intelligence technologies-enhanced brain MRI research. Multimed Tools Appl. 2020.

16. Chen X, Chen J, Cheng G, Gong T. Topics and trends in artificial intelligence assisted human brain research. PLoS One. 2020;15(4):e231192.

17. Aria M, Cuccurullo C. Bibliometrix: an R-tool for comprehensive science mapping analysis. J Inf Secur. 2017;11(4):959-75. https://doi.org/10.1016/j. joi.2017.08.007.

18. Chen X, Zou D, Cheng G, Xie H. Detecting latent topics and trends in educational technologies over four decades using structural topic modeling: a retrospective of all volumes of computers \& education. Comput Educ. 2020;151:103855. https://doi.org/10.1016/j.compedu.2020.103855.

19. Zou L, Sun L. Global diabetic kidney disease research from 2000 to 2017. Medicine. 2019;98(6):e14394. https://doi.org/10.1097/MD.0000000000014394.

20. Montinaro V, Giliberti M, Villani C, Montinaro A. Citation classics: ranking of the top 100 most cited articles in nephrology. Clin Kidney J. 2019;12(1):6-18. https://doi.org/10.1093/ckj/sfy033.

21. Chen X, Xie H. A structural topic modeling-based bibliometric study of sentiment analysis literature. Cogn Comput. 2020;12(6):1097-129. https://doi org/10.1007/s12559-020-09745-1.

22. Haynes R, Judge PK, Staplin N, Herrington WG, Storey BC, Bethel A, et al. Effects of Sacubitril/valsartan versus Irbesartan in patients with chronic kidney disease. Circulation. 2018;138(15):1505-14. https://doi.org/10.1161/ CIRCULATIONAHA.118.034818.

23. Packer M, Claggett B, Lefkowitz MP, McMurray J, Rouleau JL, Solomon SD, et al. Effect of neprilysin inhibition on renal function in patients with type 2 diabetes and chronic heart failure who are receiving target doses of inhibitors of the renin-angiotensin system: a secondary analysis of the PARA DIGM-HF trial. Lancet Diabetes Endocrinol. 2018;6(7):547-54. https://doi. org/10.1016/\$2213-8587(18)30100-1.

24. Reich HN, Oudit GY, Penninger JM, Scholey JW, Herzenberg AM. Decreased glomerular and tubular expression of ACE2 in patients with type 2 diabetes and kidney disease. Kidney Int. 2008;74(12):1610-6. https://doi.org/10.1038/ ki.2008.497.

25. Mizuiri S, Hemmi H, Arita M, Ohashi Y, Tanaka Y, Miyagi M, et al. Expression of ACE and ACE2 in individuals with diabetic kidney disease and healthy controls. Am J Kidney Dis. 2008;51(4):613-23. https://doi.org/10.1053/j.ajkd.2007.11.022.

26. Menon R, Otto EA, Sealfon R, Nair V, Wong AK, Theesfeld CL, et al. SARS-CoV-2 receptor networks in diabetic and COVID-19 associated kidney disease. Kidney Int. 2020;98(6):1502-18. https://doi.org/10.1016/j.kint.2020.09.015.

27. Vuille-dit-Bille RN, Camargo SM, Emmenegger L, Sasse T, Kummer E, Jando J, et al. Human intestine luminal ACE2 and amino acid transporter expression increased by ACE-inhibitors. Amino Acids. 2015:47(4):693-705 https://doi. org/10.1007/s00726-014-1889-6. 
28. Parit R, Jayavel $\mathrm{S}$. Association of ACE inhibitors and angiotensin type II blockers with ACE2 overexpression in COVID-19 comorbidities: a pathwaybased analytical study. Eur J Pharmacol. 2021;896:173899. https://doi.org/1 0.1016/j.ejphar.2021.173899.

29. Zhou $P$, Yang $X L$, Wang $X G$, Hu B, Zhang L, Zhang W, et al. A pneumonia outbreak associated with a new coronavirus of probable bat origin. Nature. 2020;579(7798):270-3. https://doi.org/10.1038/s41586-020-2012-7.

30. Wrapp D, Wang N, Corbett KS, Goldsmith JA, Hsieh CL, Abiona O, et al. Cryo-EM structure of the 2019-nCoV spike in the prefusion conformation. Science. 2020;367(6483):1260-3. https://doi.org/10.1126/science.abb2507.

31. Zhang H, Penninger JM, Li Y, Zhong N, Slutsky AS. Angiotensin-converting enzyme 2 (ACE2) as a SARS-CoV-2 receptor: molecular mechanisms and potential therapeutic target. Intensive Care Med. 2020;46(4):586-90. https:// doi.org/10.1007/s00134-020-05985-9.

32. Zhu L, She ZG, Cheng X, Qin JJ, Zhang XJ, Cai J, et al. Association of blood glucose control and outcomes in patients with COVID-19 and pre-existing type 2 diabetes. Cell Metab. 2020;31(6):1068-77. https://doi.org/10.1016/j. cmet.2020.04.021.

33. Stasi A, Castellano G, Ranieri E, Infante B, Stallone G, Gesualdo L, et al. SARSCoV-2 and viral sepsis: immune dysfunction and implications in kidney failure. J Clin Med. 2020;9(12):4057. https://doi.org/10.3390/jcm9124057.

34. Oussalah A, Gleye S, Clerc UI, Laugel E, Callet J, Barbé F, et al. Long-term ACE inhibitor/ARB use is associated with severe renal dysfunction and acute kidney injury in patients with severe COVID-19: results from a referral center cohort in the north east of france. Clin Infect Dis. 2020;71(9):2447-56. https://doi.org/10.1093/cid/ciaa677.

35. Lim JH, Cho JH, Jeon Y, Kim JH, Lee GY, Jeon S, et al. Adverse impact of renin-angiotensin system blockade on the clinical course in hospitalized patients with severe COVID-19: a retrospective cohort study. Sci Rep. 2020; 10(1):20250. https://doi.org/10.1038/s41598-020-76915-4.

36. Perkovic V, Jardine MJ, Neal B, Bompoint S, Heerspink H, Charytan DM, et al. Canagliflozin and renal outcomes in type 2 diabetes and nephropathy. $\mathrm{N}$ Engl J Med. 2019;380(24):2295-306. https://doi.org/10.1056/NEJMoa1811744.

37. Jardine MJ, Zhou Z, Mahaffey KW, Oshima M, Agarwal R, Bakris G, et al. Renal, cardiovascular, and safety outcomes of canagliflozin by baseline kidney function: a secondary analysis of the CREDENCE randomized trial. J Am Soc Nephrol. 2020;31(5):1128-39. https://doi.org/10.1681/ASN.2019111168.

38. Oshima $M$, Neuen $B L$, Jardine $M J$, Bakris $G$, Edwards $R$, Levin $A$, et al. Effects of canagliflozin on anaemia in patients with type 2 diabetes and chronic kidney disease: a post-hoc analysis from the CREDENCE trial. Lancet Diabetes Endocrinol. 2020;8(11):903-14. https://doi.org/10.1016/S2213 8587(20)30300-4.

39. Heerspink H, Stefánsson BV, Correa-Rotter R, Chertow GM, Greene T, Hou FF, et al. Dapagliflozin in patients with chronic kidney disease. N Engl J Med. 2020:383(15):1436-46. https://doi.org/10.1056/NEJMoa2024816.

40. Xie Y, Bowe B, Gibson AK, McGill JB, Maddukuri G, Yan Y, et al. Comparative effectiveness of SGLT2 inhibitors, GLP-1 receptor agonists, DPP-4 inhibitors, and sulfonylureas on risk of kidney outcomes: emulation of a target trial using health care databases. Diabetes Care. 2020;43(11):2859-69. https://doi. org/10.2337/dc20-1890.

41. Buse JB, Wexler DJ, Tsapas A, Rossing P, Mingrone G, Mathieu C, et al. 2019 update to: management of hyperglycemia in type 2 diabetes, 2018. A consensus report by the American Diabetes Association (ADA) and the European association for the study of diabetes (EASD). Diabetes Care. 2020; 43(2):487-93. https://doi.org/10.2337/dci19-0066.

42. Davies MJ, D'Alessio DA, Fradkin J, Kernan WN, Mathieu C, Mingrone G, et al. Management of hyperglycemia in type 2 diabetes, 2018. A consensus report by the American Diabetes Association (ADA) and the European association for the study of diabetes (EASD). Diabetes Care. 2018;41(12): 2669-701. https://doi.org/10.2337/dci18-0033.

43. Wilson PC, Wu H, Kirita Y, Uchimura K, Ledru N, Rennke HG, et al. The single-cell transcriptomic landscape of early human diabetic nephropathy. Proc Natl Acad Sci. 2019;116(39):19619-25. https://doi.org/10.1073/pnas.1 908706116.

44. Lake BB, Chen S, Hoshi M, Plongthongkum N, Salamon D, Knoten A, et al. A single-nucleus RNA-sequencing pipeline to decipher the molecular anatomy and pathophysiology of human kidneys. Nat Commun. 2019;10(1): 2832. https://doi.org/10.1038/s41467-019-10861-2.

45. Arazi A, Rao DA, Berthier CC, Davidson A, Liu Y, Hoover PJ, et al. The immune cell landscape in kidneys of patients with lupus nephritis. Nat Immunol. 2019;20(7):902-14. https://doi.org/10.1038/s41590-019-0398-x.
46. Rashidi P, Bihorac A. Artificial intelligence approaches to improve kidney care. Nat Rev Nephrol. 2020;16(2):71-2. https://doi.org/10.1038/s41581-0190243-3.

47. Zeng C, Nan Y, Xu F, Lei Q, Li F, Chen T, et al. Identification of glomerular lesions and intrinsic glomerular cell types in kidney diseases via deep learning. J Pathol. 2020;252(1):53-64. https://doi.org/10.1002/path.5491.

48. Leung RKK, Wang Y, Ma RCW, Luk AOY, Lam V, Ng M, et al. Using a multistaged strategy based on machine learning and mathematical modeling to predict genotype-phenotype risk patterns in diabetic kidney disease: a prospective case-control cohort analysis. BMC Nephrol. 2013;14:162. https:// doi.org/10.1186/1471-2369-14-162.

49. Hayashi Y. Detection of lower albuminuria levels and early development of diabetic kidney disease using an artificial intelligence-based rule extraction approach. Diagnostics. 2019;9(4):133. https://doi.org/10.3390/diagnostics904 0133.

50. Makino M, Yoshimoto R, Ono M, Itoko T, Katsuki T, Koseki A, et al. Artificial intelligence predicts the progression of diabetic kidney disease using big data machine learning. Sci Rep-UK. 2019;9(1):11862. https://doi.org/10.1038/ s41598-019-48263-5.

\section{Publisher's Note}

Springer Nature remains neutral with regard to jurisdictional claims in published maps and institutional affiliations.

\section{Ready to submit your research? Choose BMC and benefit from:}

- fast, convenient online submission

- thorough peer review by experienced researchers in your field

- rapid publication on acceptance

- support for research data, including large and complex data types

- gold Open Access which fosters wider collaboration and increased citations

- maximum visibility for your research: over $100 \mathrm{M}$ website views per year

At $\mathrm{BMC}$, research is always in progress.

Learn more biomedcentral.com/submissions 